\title{
The medical elective: A unique educational opportunity
}

R I Caldwell, ${ }^{1}$ BSc (Med), MB ChB, FCP (SA), FRCP (Lond); A C Inglis, ${ }^{1,2}$ FACEM, FCEM (UK), MB ChB, Dip Soc Admin (Oxon), DTM\&H (Liverpool), Dip Paed (AKL), Dip O\&G (AKL), Dip Med Sci (Dive\&Hyperbaric Med) (AKL); M Morgan, ${ }^{1,3}$ MB BCh, FCPaed (SA), Cert Critical Care (SA) Paed; K Rasmussen, ${ }^{1,3}$ FCP (SA), FCCH (SA), DHSM, DTM\&H, DOH; C Aldous, ${ }^{1} \mathrm{PhD}$

${ }^{1}$ School of Clinical Medicine, University of KwaZulu-Natal, Pietermaritzburg, South Africa ${ }^{2}$ KwaZulu-Natal Department of Health, Edendale Hospital, Pietermaritzburg, South Africa ${ }^{3}$ KwaZulu-Natal Department of Health, Grey's Hospital, Pietermaritzburg, South Africa

Corresponding author: R I Caldwell (ric@caldwells.co.za)

Elective medical student (EMS) programmes have existed worldwide for half a century and are voluntary placements undertaken as part of a medical degree, in a setting different from that to which the students are accustomed. ${ }^{[1,2]}$ Electives take place at an early professional age, and provide in-depth experiences, including the core values of service learning. The community, students and medical schools should all benefit from this arrangement.

Foreign students may choose South Africa (SA) for an international health elective (IHE) when their university affords them a period away from formal studies. The process involves advance paperwork and funding, whether through saving or by sponsorship. ${ }^{[3]}$ The student applies via the recipient website, or directly to a particular consultant. Registration with the Health Professions Council of SA (HPCSA) is crucial, requiring confirmation of eligibility from the student's own medical school and from the recipient SA school. Immunisation certificates, medical insurance, and provincial department of health indemnities are further necessities. Once fees are paid, the university will send a letter of acceptance. A tourist visa suffices if the visit is shorter than 3 months; otherwise, a study visa is required. Word-of-mouth information can result in a succession of IHEs to specific departments.

When SA students, already HPCSA registered, seek electives at other SA hospitals, parent institutions only require an appropriate supervisor rather than acceptance by another medical school.

There are also 'non-elective' applicants, i.e. SA citizens who, having not gained admission to a local medical school, are studying abroad. Their parent medical school requires a year's clinical tuition in another country, including detailed documentation thereof. This is not a voluntary IHE, which merely requires a certificate of attendance.

\section{Benefits of medical electives The student and the community}

IHE students experience a different system of medicine in exotic surroundings, and are taken out of their comfort zones, observing the advantages and disadvantages of the foreign training. SA has patients with a wide range of illnesses that students overseas may not be exposed to. EMS programmes, embodying the concepts of person-centred and communityorientated care, allow these students to expand their knowledge base and skills under supervision.

EMSs from SA universities will be able to observe how other medical professionals in the public health service deal with similar problems, thus acquiring a different approach to working in the developing world.

\section{The recipient institution and medicine}

Medicine is globalised, and therefore any gains to a student are to the credit of the recipient medical school. ${ }^{[4]}$ This 'bigger picture' fits the mantra: 'think globally, act locally'. IHE students, observing what developing countries deal with, may in time influence policymakers. They may provide insight into management of similar conditions in their own countries. Research is also a possibility. EMSs are popular with other medical personnel, as was obvious on rural outreach visits.

There is evidence, both published and gained in person by three of the authors during outreach visits, suggesting that staffing of rural hospitals by foreign junior doctors is in accordance with IHEs. ${ }^{[5,6]}$ These doctors, or their colleagues, had been EMSs as undergraduates, recommending hospitals noted for sound clinical experience under good supervision. No student should act unethically, e.g. by undertaking unsupervised clinical responsibilities beyond their level of capability. ${ }^{[7]}$

SA medical school EMSs undertaking an elective elsewhere in SA might well consider internship, community service and beyond in the centre visited - a win-win outcome.

\section{Drawbacks of IHEs/EMSs}

There may be concern that EMSs could make undue demands on recipient consultants. However, the relevant department accepts such students only when it has the space and time for them.

'Medical tourism' has been criticised, as the net gain favours the trainee participant and insufficient consideration is given to the needs of the host country. ${ }^{[8]}$ Nevertheless, the same authors acknowledge that even medical tourism increases involvement in global medicine. ${ }^{[8]}$ EMSs come with a set of socially responsible objectives from their university. In our experience, most of them exceed the requirements and are anything but medical tourists.

\section{Designing an EMS programme}

While it is important not to over-regulate this fragile asset, administration needs to be efficient and user friendly. The following suggestions may be useful to institutions offering EMS and/or IHE programmes:

- The elective experience should be based on international professional and ethical standards.

- Potential EMSs should include a CV and details regarding their expectations from the elective. Preferred dates may be requested, up to a maximum of 16 weeks' duration.

- Applications should not proceed without a department's acceptance of the EMS (automatically governing saturation).

- University 'processing' should ensure that HPCSA registration takes priority; 3 - 4 months should suffice, with the onus on the student to complete the paperwork promptly.

- EMSs from SA medical schools should not pay a fee, other than for accommodation.

- Occupational health risks are real. An induction course in the first week is advisable, emphasising HIV- and tuberculosis-related issues. 


\section{Forum}

- The funds generated through IHEs could be used to enhance the programme, including sponsorship of local students for their own electives. Encouragement should be given to the institution's own students towards undertaking elective periods, either as an IHE student or elsewhere in SA.

\section{Conclusion}

This article supports medical electives that benefit the community, the student and higher educational institutions. It identifies a 'non-elective' group, which needs attention. The objective is to provide an elective opportunity that will help to create 21st-century health professionals, including clinical involvement and encouragement towards enjoyment and appreciation of SA.

\section{Acknowledgements. None.}

Author contributions. All the authors complied with the International Committee of Medical Journal Editors' rules of authorship and were part of formulating and conceptualising the article. Although the initial draft was prepared by the first author, subsequent work on the manuscript included inputs from all authors.
Funding. None.

\section{Conflicts of interest. None.}

1. Edwards R, Piachaud J, Rowson M, Miranda J. Understanding global health issues: Are international medical electives the answer? Med Educ 2004;38(7):688-690. https://doi.org/10.1046/j.1365-2929.2004.01849.x

2. O’Donnell P, McAuliffe E, O'Donovan D. Unchallenged good intentions: A qualitative study of the experiences of medical students on international health electives to developing countries. Hum Resource Health 2014;12(1):49. https://doi.org/10.1186/1478-4491-12-49

3. Gulsin GS, Johnston PW. Funding your elective. Student BMJ. http://student.bmj.com/student/view-article. html?id=sbmj.d5851 (accessed 4 October 2017).

4. Jeffrey J, Dumont RA, Kim GY, Kuo T. Effects of international health electives on medical student learning and career choice: Results of a systematic literature review. Fam Med 2011;43(1):21-28.

5. Dolea C, Stormont L, Braichet J-M. Evaluated strategies to increase attraction and retention of health workers in remote and rural areas. Bull World Health Organ 2010:88(5):379-385. https://doi.org/10.2471/BLT.09.070607

6. Thompson MJ Hut electives on US and Ca https//doi.org/10.1097/00001888-200303000-00023

7. Flit L Hunt M, Redwood-Campbell L Ranford J Adelson N, Schwartz L. Ethical issues encountered by medica students during international health electives. Med Educ 2011;45(7):704-711. https://doi.org/10.1111/j.13652923.2011.03936.x

8. Petrosoniak A, McCarthy A, Varpio L. International health electives: Thematic results of student and professional interviews. Med Educ 2010;44(7):683-689. https://doi.org/10.1111/j.1365-2923.2010.03688.x

Accepted 9 May 2017.

Afr J Health Professions Educ 2017;9(4):162-163. DOI:10.7196/AJHPE.2017.v9i4.883 